\title{
Response of the equatorial ionosphere to the total solar eclipse of 22 July 2009 and annular eclipse of 15 January 2010 as observed from a network of stations situated in the Indian longitude sector
}

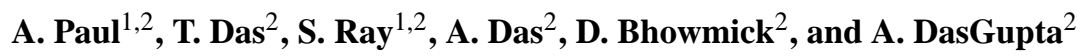 \\ ${ }^{1}$ Institute of Radio Physics and Electronics, University of Calcutta, Calcutta, India \\ ${ }^{2}$ S. K. Mitra Center for Research in Space Environment, University of Calcutta, Calcutta, India
}

Received: 11 October 2010 - Revised: 28 July 2011 - Accepted: 3 October 2011 - Published: 31 October 2011

\begin{abstract}
Dual-frequency GPS TEC monitors have been used to study the response of the ionosphere to the solar eclipses of 22 July 2009 and 15 January 2010. The receivers were located at three stations, Calcutta, Kharagpur and Baharampore which are situated outside the umbra zone in the Indian longitude sector with each baseline being $\sim 200 \mathrm{~km}$. Effects of obscuration of the solar disc were noted in the ambient TEC recorded at the three stations. A series of depletions in TEC along the track of a GPS satellite and associated wave-like structures were identified on some GPS links during both the eclipses.
\end{abstract}

Keywords. Ionosphere (Equatorial ionosphere; Ionospheric disturbances) - Radio science (Waves in plasma)

\section{Introduction}

A solar eclipse provides a unique opportunity to study the ionospheric response to the sudden withdrawal of solar radiation. Two consequences have so far been recognized over the years: (1) the generation of gravity waves due to the transit of locally cooled region of the atmosphere moving at supersonic speed (Chimonas and Hines, 1970), and (2) a reduction in the plasma density as the source of ionization is switched off (Van Zandt et al., 1960). The Earth's atmosphere may produce wave motions due to localized timedependent heating or cooling action. A solar eclipse, by interfering with the heat balance in the shadowed portion of the atmosphere, is expected to generate Atmospheric Gravity Waves (AGW). These AGWs could interfere to produce a bow wave detectable at large distances from the eclipse path

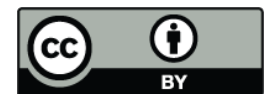

Correspondence to: A. Paul (ashik_paul@rediffmail.com) at ground level and at ionospheric heights. The gravity waves could manifest themselves as Travelling Ionospheric Disturbances (TIDs). Chimonas (1970) and Chimonas and Hines (1970) estimated the amplitude and phase of the periodic disturbances generated by an eclipse at ionospheric heights away from the umbra region and had shown that the bearing of the source at an observing point plays an important role. While Davis and da Rosa (1970) found some evidences of TIDs associated with the 7 March 1970 total solar eclipse in USA, many null results have also been reported for eclipses observed later from different regions of the Earth.

The source of gravity waves was initially assumed to be either at higher altitudes around $90 \mathrm{~km}$ where molecular oxygen heating begins (Chimonas, 1970), or at lower altitudes e.g. water vapor IR absorption (Lamb waves) and the ground cooling (Chimonas and Hines, 1971; Chimonas, 1973). The disturbance of the heat balance during an eclipse was attributed to the cooling caused by the supersonic movement of the moon's shadow on the ozone layer (Zerefos et al., 2000). Theoretical approaches to the eclipse induced gravity waves' generation and propagation reveal a bow wave structure (forward and outward from the eclipse track) with horizontal and vertical scales of 5000-10000 km and $200 \mathrm{~km}$, respectively, while the wave amplitudes were found to increase dramatically with altitude, due to the density decrease with height (Fritts and Luo, 1993). Concerning the wave periods, Chimonas and Hines (1971) calculated an order of $20 \mathrm{~min}$ at $5000 \mathrm{~km}$ from the source and about $4 \mathrm{~h}$ at more than $10000 \mathrm{~km}$. However, Fritts and Luo (1993) computed that the dominant period is $2-4 \mathrm{~h}$ for distance from the source between 5000 and $10000 \mathrm{~km}$. Along the path of the eclipse the extra wave energy could tend to be spatially focused leading to interference effects such as amplitude enhancement or additional frequency dispersion, resulting to variable gravity wave characteristics during different eclipses (Chimonas and Hines, 1970).

Published by Copernicus Publications on behalf of the European Geosciences Union. 
In the ionosphere waves with a period of 10-40 min have been measured at more than $500 \mathrm{~km}$ from the zone of totality (Singh et al., 1989), traveling at subsonic (Davis and da Rosa, 1970) or supersonic velocities (Hanuise et al., 1982). A source location has been identified in the thermosphere at $170 \mathrm{~km}$ altitude, based on the analysis of ionosonde measurements (Liu et al., 1998; Altadill et al., 2001; Sauli et al., 2006), while larger periods of about $1 \mathrm{~h}$ have also been reported (Altadill et al., 2001).

Studies on the ionospheric response to solar eclipses have been conducted from India for the last six decades. During the 16 February 1980 solar eclipse, ionospheric Total Electron Content (TEC) was measured using Faraday rotation technique by recording VHF (136 MHz) transmission from a geostationary satellite in India. Tyagi et al. (1980), DasGupta et al. (1981) and Deshpande et al. (1982) initially did not observe any signatures of TIDs from visual examinations of the data recorded on strip charts. Singh et al. (1989) from a detailed analysis of the data reported that TIDs were detected at distances more than $500 \mathrm{~km}$ away from the umbra region. Theoretical estimates show that the period and amplitude of gravity waves is dependent on the bearing of the source with respect to the observing point in the ionosphere (Chimonas, 1970; Vadas, 2007). First experimental signatures of the existence of gravity waves were observed with periodicity of 30-33 min in ionosphere. However various results of the solar eclipse observations arise from the fact that different solar eclipses produce different plasma motions. Farges et al. (2001) suggested a longitudinal diversity of the disturbances with respect to pre-noon and post-noon phases.

A multi station dual frequency GPS (Global Positioning System) network was operated by the Satellite Beacon Group of the S. K. Mitra Center for Research in Space Environment, University of Calcutta, Calcutta, India during the total solar eclipse on 22 July 2009 and the annular eclipse of 15 January 2010 for measuring the ionospheric TEC and other parameters. The stations used were located at the Institute of Radio Physics and Electronics, University of Calcutta, Calcutta $\left(22.58^{\circ} \mathrm{N}, 88.38^{\circ} \mathrm{E}\right.$ geographic, magnetic dip: $\left.32^{\circ} \mathrm{N}\right)$, Indian Space Research Organization (ISRO) Regional Remote Sensing Service Center (RRSSC) at the Indian Institute of Technology (IIT), Kharagpur $\left(22.33^{\circ} \mathrm{N}, 87.36^{\circ} \mathrm{E}\right.$ geographic, magnetic dip: $31.5^{\circ} \mathrm{N}$ ) situated about $200 \mathrm{~km}$ west of Calcutta and K. N. College, Baharampore $\left(24.09^{\circ} \mathrm{N}\right.$, $88.25^{\circ} \mathrm{E}$ geographic, magnetic dip: $35^{\circ} \mathrm{N}$ ) about $200 \mathrm{~km}$ north of Calcutta, thereby forming a triangular network with base lines of the order of $200 \mathrm{~km}$. The path of the total solar eclipse passed over these three stations during 00:00 to 02:00 UT on 22 July 2009 and during 07:30-10:30 UT on the day of the annular eclipse on 15 January 2010. To the best of our knowledge, this was the first multi-station GPS campaign conducted in the geophysically sensitive Indian longitude sector in connection with a solar eclipse. The main objective of performing the experiment was detection of Trav- eling Ionospheric Disturbances (TIDs) suggested being manifestations of AGWs associated with solar eclipses and their characterization with respect to period and propagation.

Since eight to twelve GPS satellites are simultaneously visible from a single station sampling different points in the ionosphere, the validity of the theoretical predictions about the period and propagation of the disturbances could be tested. By combining observations from a number of stations, the source of the AGWs can be located with reverse ray tracing. It has been suggested that the perturbation amplitude are less than $1 \%$ of the ambient TEC at distances greater than $500 \mathrm{~km}$ and the TID period is a function of the distance. In India the total solar eclipse occurred in the morning hours when the ambient ionization is low. It should therefore be noted that detection of TIDs by the GPS monitors at large distances from the umbra zone will depend on the sensitivity of the receivers and proper filtering of the data. The present paper reports some initial findings of the response of the lowlatitude ionosphere to solar eclipses using the multi-station GPS campaign conducted in 2009 and 2010.

\section{Data}

During the solar eclipse campaign, TEC was measured using the GPS receivers at three stations, namely, Calcutta $\left(22.58^{\circ} \mathrm{N}, 88.38^{\circ} \mathrm{E}\right.$ geographic, magnetic dip: $\left.32^{\circ} \mathrm{N}\right)$, Kharagpur $\left(22.33^{\circ} \mathrm{N}, 87.36^{\circ} \mathrm{E}\right.$ geographic, magnetic dip: $\left.31.5^{\circ} \mathrm{N}\right)$ and Baharampore $\left(24.09^{\circ} \mathrm{N}, 88.25^{\circ} \mathrm{E}\right.$ geographic, magnetic dip: $35^{\circ} \mathrm{N}$ ), for some weeks before and after the total solar eclipse of 22 July 2009 and the annular eclipse on 15 January 2010.

The station at Calcutta is part of the international SCINDA (SCIntillation Network Decision Aid) program of the US Air Force since November 2006 whereby a dual frequency Ionospheric Scintillation and TEC Monitor is operational continuously providing diurnal TEC plots, scintillation indices S4 and $\sigma_{\phi}$ and polar plots corresponding to different satellites observed during the whole day. These data may be accessed in a post-processed format by authorized users. The raw data are continuously uploaded to the SCINDA website (http://scinda.aer.com).

A software-based dual-frequency high resolution GPS receiver capable of measuring TEC with an accuracy of $5 \times$ $10^{-4}$ TEC units was operated at the ISRO-RRSSC at IITKharagpur for 2 weeks around the total solar eclipse on 22 July 2009 and the annular eclipse on 15 January 2010. This receiver may be configured for various data recording schedules as per user requirements. Amplitude and phase scintillation data from this receiver was digitally logged at $17 \mathrm{~Hz}$ sampling frequency while the TEC data was recorded at 1 min sampling interval.

Another dual frequency Ionospheric Scintillation and TEC Monitor was operated at K. N. College, Baharampore for a period of few weeks covering the 22 July 2009 total solar 

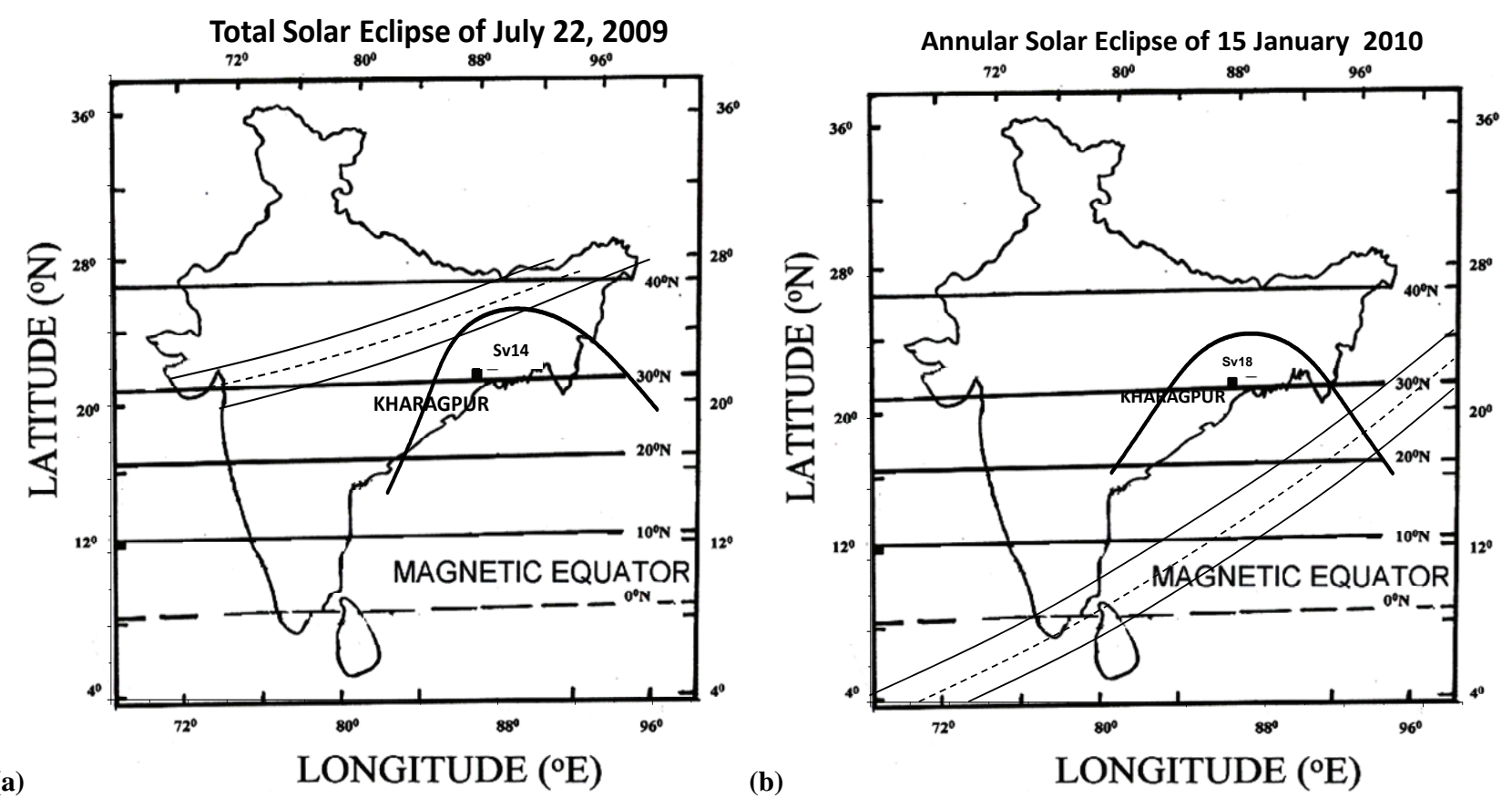

Fig. 1. Path of totality of the solar eclipse on 22 July 2009 over the Indian subcontinent and the track of SV14 observed from Kharagpur is shown in (a) and the path of the annular eclipse on 15 January 2010 with the track of SV18 observed from Kharagpur is shown in (b). The location of the Kharagpur is also shown in the map.

eclipse and the annular eclipse on 15 January 2010. Ionospheric TEC measured by the receiver were recorded at $1 \mathrm{~min}$ sampling interval.

\section{Results}

Figure 1a shows the path of totality of the 22 July 2009 solar eclipse with the track of the GPS satellite SV14 observed from Kharagpur and Fig. 1b shows the path during the annular eclipse of 15 January 2010 with the track of SV18 observed from the same station. The location of Kharagpur during the campaign is also shown in Fig. 1. It may be noted that Kharagpur is situated about $200 \mathrm{~km}$ west of Calcutta while Baharampore is located about $200 \mathrm{~km}$ north of Calcutta, thereby forming a triangular network with base lines of the order of $200 \mathrm{~km}$. Table 1 summarizes the details of the above two eclipses as observed from the three stations, namely, Calcutta, Kharagpur and Baharampore.

During the period of the eclipse starting from the first contact around 23:58 UT of 21 July 2009 to the last contact at 02:01 UT of 22 July 2009, a number of GPS satellites, namely, SV01, SV06, SV09, SV14, SV18, SV21, SV22, SV24, SV26, SV27, SV30 and SV31 were visible from the three stations. In order to understand the variation of TEC, if any, on the days of the two eclipses in comparison to a normal day, GPS slant TEC measurements from different satellites above an elevation angle of $15^{\circ}$ were combined to produce the diurnal plots on days preceding and following the day of the eclipse. Figure 2a, b and c corresponds to diurnal variation of slant TEC as observed from Kharagpur during the period 20-21 July through 22-23 July 2009 respectively. It should be noted that plots from a particular station presented in the paper are representative of the entire network of three stations. As Fig. 2 contains data from a number of GPS satellites which were tracked from Kharagpur, a polynomial curve of degree 5 plotted in bold was fitted to best represent the diurnal variation on the above-mentioned three days which is also shown in Fig. 2. It is observed that the early morning growth of ionization during the period 23:30 UT of 21 July 2009 through 02:30 UT of 22 July 2009 was delayed on the day of the eclipse in comparison to the day before and the day after. Comparing the best-fit polynomial curves for the three days, namely, 20-21 July through 22-23 July 2009 in Fig. 3, it was found that on 22 July 2009, the day of the total solar eclipse, there was a decrease of $10 \%$ from the ambient level of TEC during the period 00:00-02:00 UT (05:3007:30 IST). Percentage contribution of the plasmasphere to TEC at low latitudes is small as a satellite link passed through field tubes at relatively large propagation angles (angle between magnetic field and ray path). The decrease in the total content is about $10 \%$ on 22 July 2009 . The plasmasphere electon content changes are unlikely to influence the total content by such a large value (Davies et al., 1976). The decrease in TEC during the morning hour 00:00-02:00 UT may thus be attributed to the reduced photoionization due to obscuration of the solar disc. The large change in the diurnal 
(a)

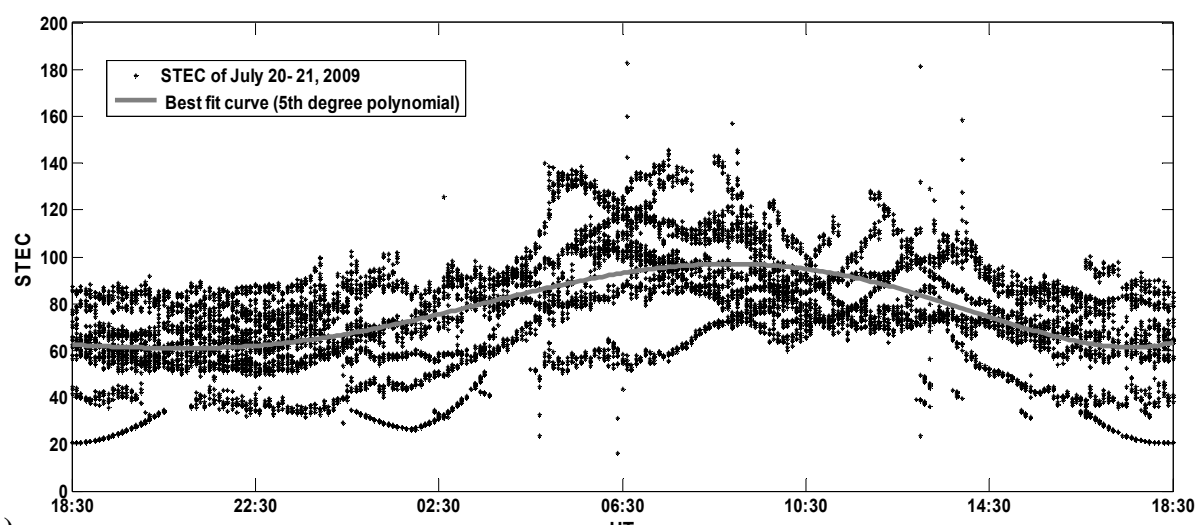

(b)

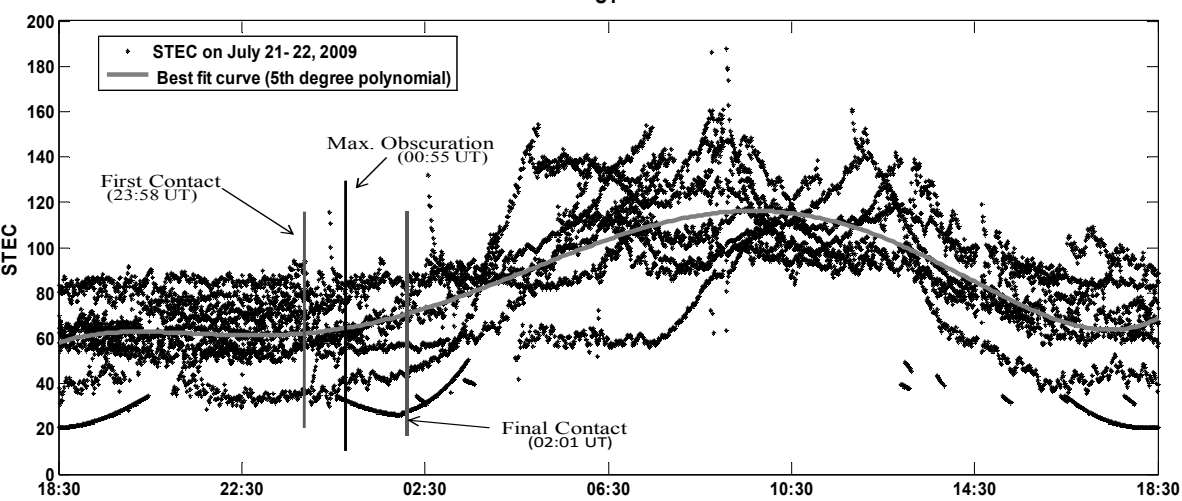

b)

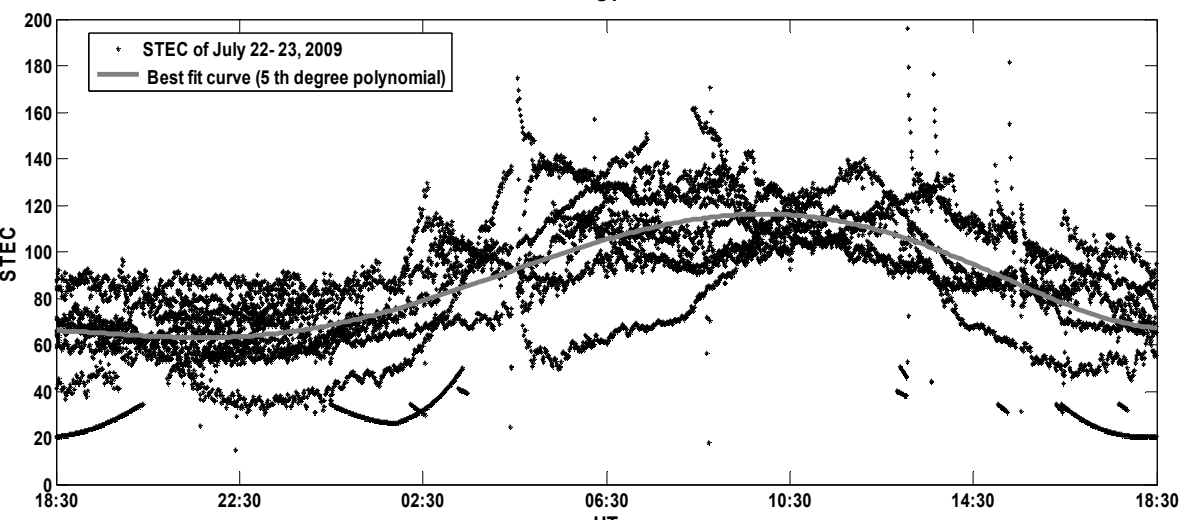

(c)

Fig. 2. Diurnal variation of slant TEC (STEC) as observed from Kharagpur during the period 20-21 July 2009, 21-22 July 2009, 2223 July 2009 are shown in (a), (b) and (c) respectively. A polynomial of degree 5 which best fits the variation is shown in bold.

maximum particularly on 20-21 July 2009 is possibly due to the reduced value of the equatorial electrojet.

Figure 4 shows the tracks of seven satellites observed from the station Kharagpur during 21-22 July 2009. The initial contact, maximum obscuration and final contact points on the satellite tracks are marked by different symbols. The 12 days average TEC (15-26 July 2009) for different satellites are plotted in Fig. 5 as dotted lines. The solid line represents the TEC of 22 July 2009 for that respective satellite. In the plot, the standard deviation of TEC of the 12 days $( \pm 1 \sigma)$ is plotted as a vertical bar. It is found that during the morning hours (00:00-02:00 UT) there is a decrease of TEC below the $-1 \sigma$ value on the eclipse day. The points of maximum obscuration and final contact are also shown in the TEC plot.

Some of the GPS links exhibited depletions in TEC before as well as after the final contact of the total solar eclipse. As the AGWs are produced subsequent to the passage of the shadow over the surface of the Earth, depletions in TEC from the ambient level that occurred after the onset of the eclipse have only been considered. The amplitudes of these depletions in TEC have been characterized using the standard procedure of taking the differences of the measured slant TEC values from the 90 min moving average. Only those depletions with an amplitude in excess of 1 TEC unit 
Table 1. The details of the 22 July 2009 and 15 January 2010 eclipses as observed from the three stations, namely, Calcutta, Kharagpur and Baharampore.

\begin{tabular}{|c|c|c|c|c|c|c|}
\hline Eclipse & Station & $\begin{array}{l}\text { First contact } \\
\text { (UT) }\end{array}$ & $\begin{array}{c}\text { Max obstruction } \\
\text { (UT) }\end{array}$ & $\begin{array}{l}\text { Final contact } \\
\text { (UT) }\end{array}$ & $\%$ of obstruction & $\begin{array}{l}\text { Magnitude } \\
\text { at max }\end{array}$ \\
\hline \multirow{6}{*}{22 Jul 2009} & Calcutta & $23: 58: 48.9$ & $00: 56: 24.8$ & 02:01:00.3 & \multirow{2}{*}{$90.41 \%$} & \multirow{2}{*}{0.91407} \\
\hline & & $21 \mathrm{Jul} 2009$ & 22 Jul 2009 & 22 Jul 2009 & & \\
\hline & Kharagpur & $23: 58: 42.0$ & $00: 55: 58.7$ & 01:59:51.3 & \multirow{2}{*}{$90.60 \%$} & \multirow{2}{*}{0.91245} \\
\hline & & $21 \mathrm{Jul} 2009$ & 22 Jul 2009 & 22 Jul 2009 & & \\
\hline & Baharampore & 23:59:14.6 & 00:57:01.8 & 02:01:43.7 & \multirow{2}{*}{$96.48 \%$} & \multirow{2}{*}{0.96213} \\
\hline & & $21 \mathrm{Jul} 2009$ & 22 Jul 2009 & 22 Jul 2009 & & \\
\hline \multirow{3}{*}{15 Jan 2010} & Calcutta & $06: 37: 22.1$ & $08: 27: 38.1$ & 09:59:07.0 & $75.97 \%$ & 0.83468 \\
\hline & Kharagpur & $06: 34: 21.3$ & $08: 25: 42.7$ & 09:58:05.7 & $74.61 \%$ & 0.82261 \\
\hline & Baharampore & $06: 39: 29.9$ & $08: 28: 24.0$ & 09:59:05.2 & $72.01 \%$ & 0.89921 \\
\hline
\end{tabular}

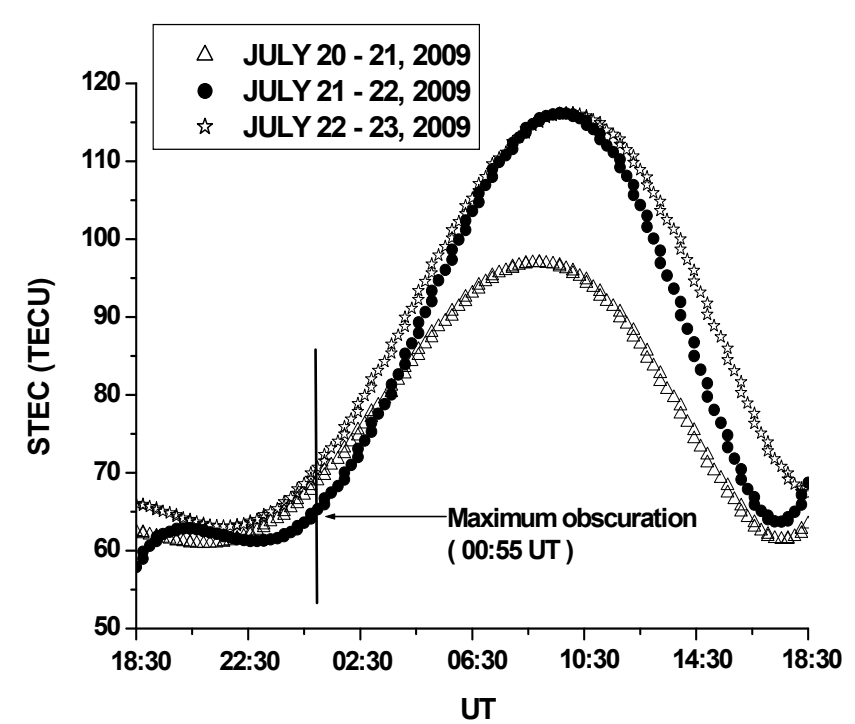

Fig. 3. Best-fit polynomial curves for the three days, namely, 2021 July through 22-23 July 2009.

at an elevation angle greater than and equal to $30^{\circ}$ have been selected for the present analysis. On 22 July 2009, SV14 moved from a location south-west of Kharagpur to south-east through north-west and north-east. Figure 6a shows the 350$\mathrm{km}$ subionospheric track of SV14 from 21:43 to 04:59 UT during 21-22 July 2009 and Fig. 6b the corresponding variation of slant TEC along its track. The 90-min moving average of the TEC is also plotted in the same figure. Nine depletions in TEC in excess of 1 TEC unit at an elevation angle greater than and equal to $30^{\circ}$ were observed with a majority of them occurring about $1 \mathrm{~h}$ to $1.5 \mathrm{~h}$ after the final contact at locations north-east of Kharagpur. These depletions have also been indicated on the track of SV14 plotted in Fig. 6a. A maximum TEC depletion of 7.6 TEC units was noted at 01:38 UT of 22 July 2009 on the SV14 link. On that day, SV16 showed eight TEC biteouts during its transit from a location south of
Kharagpur to north-east of the station with majority of them occurring around 05:10 UT. Similar features were observed by SV22 during 01:30 to 02:30 UT and SV31 during 02:30 to $05: 15$ UT. The GPS link SV18 showed two depletions in excess of 1 TEC unit around 01:30UT. SV20 whose track passed south-west of Kharagpur to the north-west exhibited five TEC biteouts between 04:30 and 05:00 UT. Similarly SV32 which had an almost identical track as that of SV20 showed eight TEC depletions in excess of 1 TEC unit at elevation angles greater than $30^{\circ}$ during 03:30 and 05:10 UT.

The amplitude of TEC depletions were distributed according to the time of their occurrences and arranged in the form of a block shown in Fig. 7. The different shades on the block indicate number of depletions of particular amplitude observed during a specific $1 \mathrm{~h}$ time interval. It is interesting to note that 36 out of 49 TEC depletions in excess of 1 TEC unit above an elevation of $30^{\circ}$ occurred during the time interval 02:30-05:30 UT following the final contact of the eclipse at 02:01 UT. The median value of these depletions was found to be about 3 TEC units while the maximum was 7.9 TEC units.

Occurrence of a series of depletions along the path of a GPS satellite is indicative of the existence of TIDs. As AGWs manifest themselves as TIDs at ionospheric heights, parameterization of wave-like structures, if any, using wavelet transform methods were employed for individual GPS links which exhibited a series of depletions in TEC along the subionospheric track. The results corresponding to SV14 are presented in Fig. 8a. Using the slant TEC recorded on the SV14 link during a period 00:57-05:11 UT on 22 July 2009, the deviations from the 90-min moving average were calculated and fed as input to the wavelet transform utility. Contours of different intensities were produced with the white ellipse indicating the cone of influence within which results are reliable. Wavelet analysis is performed from the point of closest approach (00:57 UT) of the $350 \mathrm{~km}$ subionospheric track of the satellite to the path of totality. Within the cone of influence the contours have an eye around 


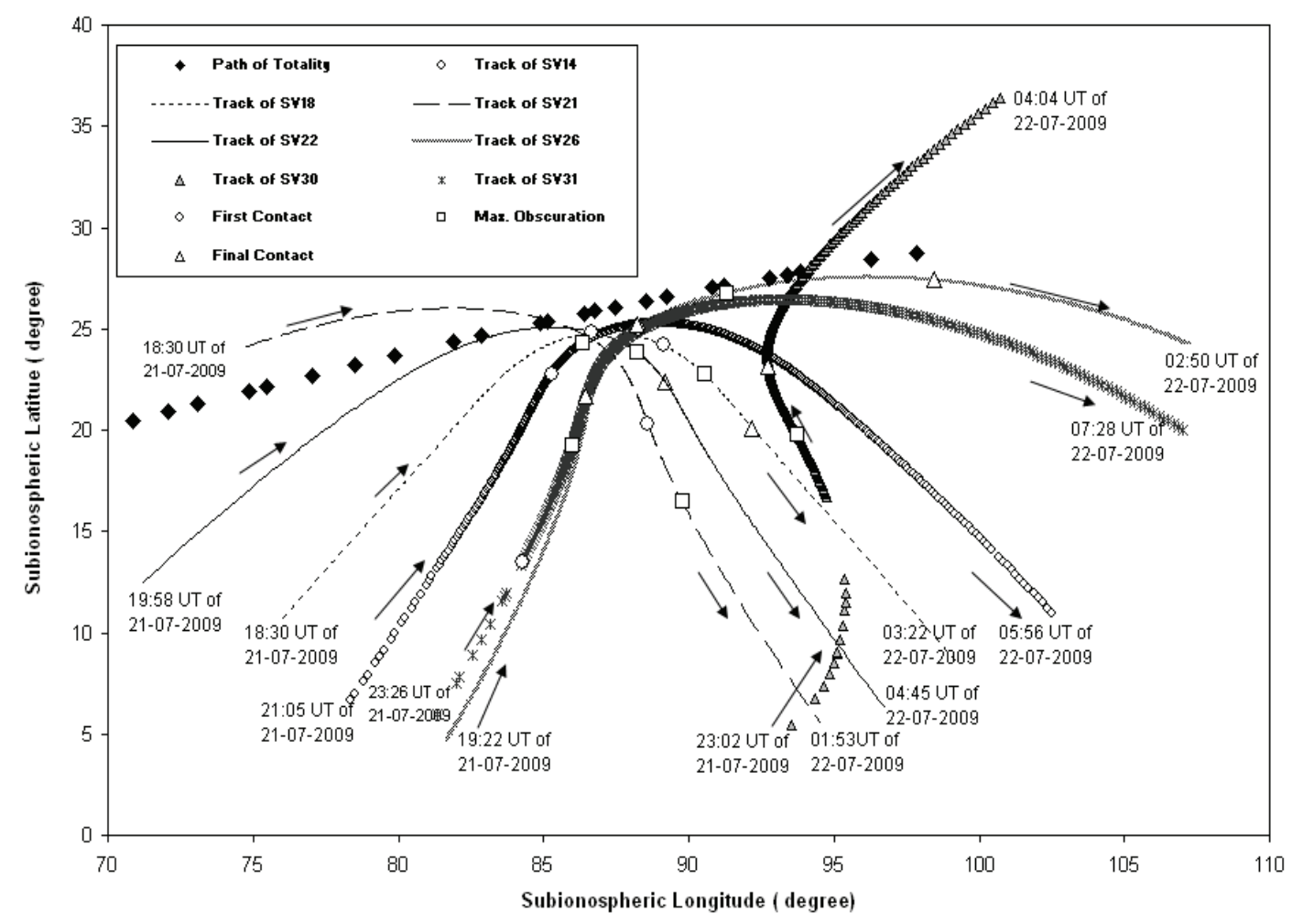

Fig. 4. The tracks of SV14, SV18, SV21, SV22, SV26, SV30 and SV31 during 21-22 July 2009 observed from Kharagpur. The first contact, maximum obscuration and the final contact on each satellite track are shown by circle, square and triangle respectively. The path of totality is also shown in the figure.

03:39 UT with a period of about $16.6 \mathrm{~min}$. This value corresponds to a medium scale travelling ionospheric disturbances. At that time, the satellite was located north-east of Kharagpur as evident from the polar plot of Fig. 8b. Similar periodic structures were noted on SV16 around 03:51 UT situated south-east of Kharagpur and on SV31 around 04:39 UT located north-east of Kharagpur, both occurring about 2-3 h after the final contact. The periodicities of AGWs detected are different from earlier reported results which may be attributed to the fact that the locations of the three stations used in the present analyses were less than $500 \mathrm{~km}$ from the umbra region.

It is of interest to note that on 22 July 2009 a small patch of amplitude scintillation was observed on the $250 \mathrm{MHz}$ geostationary FLEETSATCOM link from Calcutta during 00:5000:55 UT. The pattern recorded was quasi-periodic with a maximum $\mathrm{S}_{4}$ index of 0.47 (SI $-11 \mathrm{~dB}$ ) during 00:5200:53 UT. Using VHF spaced-aerial measurements, the drift velocity of the irregularities were found to be westward and lying within a range of $28-45 \mathrm{~m} \mathrm{~s}^{-1}$ during the above time interval. The power spectrum of amplitude scintillations showed signatures of Fresnel oscillations, indicating that the irregularity layer was very thin (Singleton, 1974). The scintillation patches may probably be attributed to Sporadic E layer. Chen et al. (2010) reported the occurrence of Sporadic E over extended areas near the path of totality in China for the same solar eclipse. Figure 9a shows the patch of scintillation observed on the VHF link from Calcutta on two antennas while Fig. 9b shows the corresponding power spectrum during 00:52-00:53 UT. Fresnel oscillation type modulations are observed superimposed on decreasing spectral power of the fluctuation with a first null $\left(f_{1}\right)$ around $1.36 \mathrm{~Hz}$ and subsequent nulls at $0.857 f_{1}, 0.776 f_{1}, 0.713$ $f_{1}, 0.67 f_{1}$. It should be mentioned that a moderate magnetic storm was in progress during the period of observation. Figure 10 shows the variation of Auroral Electrojet Index (AE), Interplanetary Magnetic Field IMF $B_{\mathrm{Z}}$, Disturbed Storm Time index (Dst) and rate of change of Dst during 21-25 July 2009. The AE value in the top frame (Fig. 10a) showed a surge $(224 \mathrm{nT})$ around 01:00 UT reaching a maximum of $305 \mathrm{nT}$ around 03:00 UT of 22 July 2009. In the second frame (Fig. 10b) the IMF $B_{\mathrm{Z}}$ at the satellite Advanced Composition Explorer (ACE) turns southward to the value less than $-5 \mathrm{nT}$ at 23:00 UT on 21 July 2009. The disturbance reached the magnetopause about $1 \mathrm{~h} 17 \mathrm{~min}$ later (approximately 00:17 UT of 22 July 2009). The IMF $B_{\mathrm{z}}$ attained a southward value of less than $-5 \mathrm{nT}$ for about $5 \mathrm{~h}$ (23:00 UT of 21 July 2009-04:00 UT of 22 July 2009). The third frame (Fig. 10c) shows the variation of Dst during the above days. In the bottom frame (Fig. 10d) $d$ Dst $/ d t$ was in 


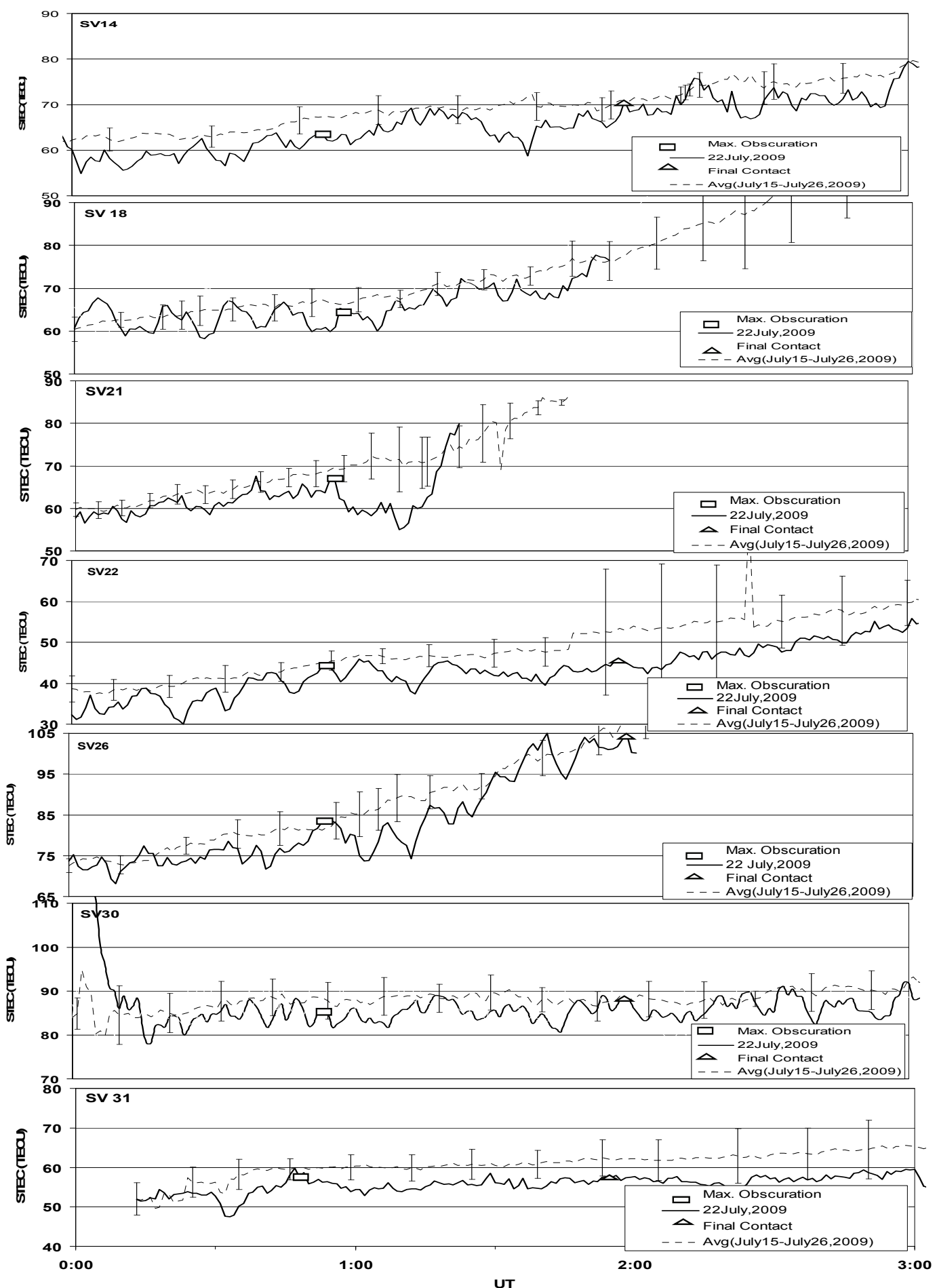

Fig. 5. The 12 days average STEC (15-26 July 2009) is shown by dotted line. The black solid line represents TEC of 22 July 2009 . The vertical lines are the standard deviation of STEC $( \pm 1 \sigma)$ of these days.

excess of $-20 \mathrm{nT}$ for about $3 \mathrm{~h}$ during 02:00-05:00 UT. The effect of magnetic storm if any is likely to contaminate the results after $B_{\mathrm{Z}}$ turning through prompt penetration of the magnetospheric electric field to the low latitudes.
During the annular solar eclipse of 15 January 2010, the best-fit diurnal plots using a polynomial curve of degree 5 for the period 13-14 January through 15-16 January 2010 are shown in Fig. 11. The TEC variation on 15 January 2010 


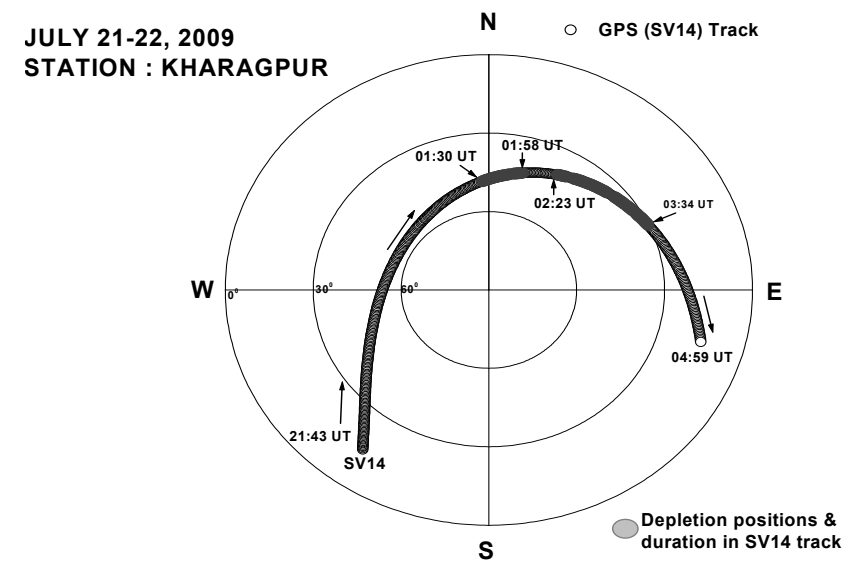

(a) TIME: 21:43 UT OF JULY 21,2009 - 04:59 UT OF JULY 22,2009

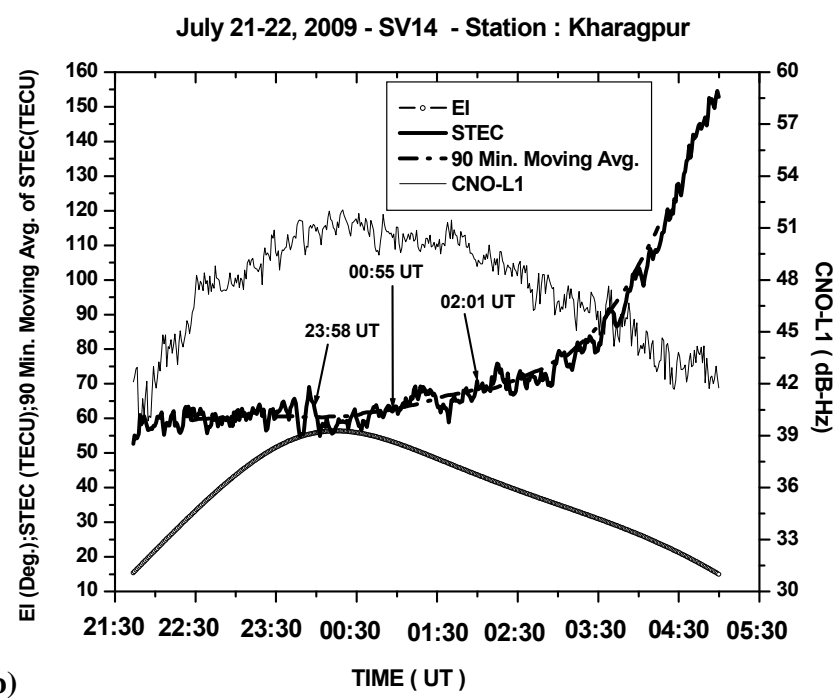

Fig. 6. The track of GPS SV14 on 22 July 2009 from 21:30 to 05:00 UT is shown in (a) and the corresponding variation of slant TEC (STEC) along its track is shown in (b). The elevation angles of the satellite, 90-min moving averages of STEC and carrier-tonoise ratios at GPS L1 frequency (CNO-L1) are also plotted in (b).

and 16 January 2010 follow the same pattern up to 06:30 UT. With the 1st contact at 06:37 UT the TEC value becomes less than that of 16 January 2010. With maximum obscuration at 08:28 UT on 15 January 2010, the deviation is $7 \%$. Even after the final contact the same trend is followed but at a lower level.

On this day, depletions in TEC were noted on some GPS links, notable among them being SV18 which showed eighteen depletions in TEC greater than 1 TEC unit at elevation angles in excess of $30^{\circ}$ along its track. Figure 12a shows the variation of slant TEC along the track of SV18 during 06:50-14:24 UT. Figure 12b shows the corresponding polar plot from Kharagpur. Waves with periodicities of $8 \mathrm{~min}$ were detected in the wavelet spectrum of SV18 TEC around 10:35 UT as depicted by the eye of the contour in Fig. 12c.

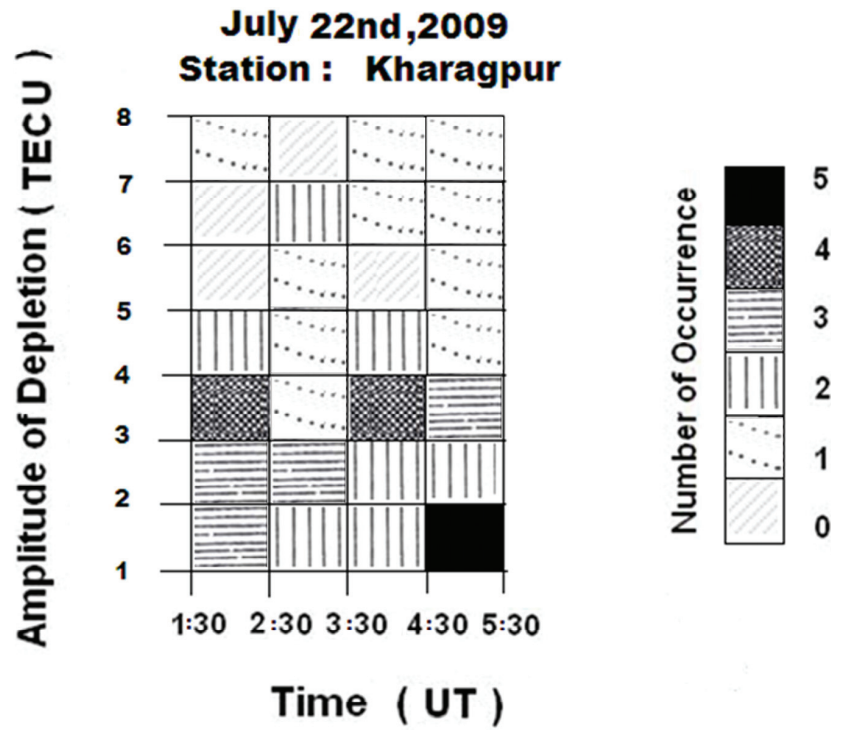

Fig. 7. Amplitude of TEC depletions in excess of 1 TEC unit above an elevation angle of $30^{\circ}$ distributed according to the time of their occurrences and arranged in the form of a block. The different shades on the block indicate number of depletions of particular amplitude observed during a specific $1 \mathrm{~h}$ time interval.

At that time, the satellite was located almost due north of the station as shown in Fig. 12b. As AGWs are expected to be generated following the passage of the lunar shadow, the eye of the contour formed around 08:00 UT may not be attributed to eclipse induced wave structures.

\section{Discussions}

The present paper reports some initial results of a multistation GPS campaign conducted in eastern India involving a triangular network of 3 stations with baselines of about $200 \mathrm{~km}$ during the total solar eclipse of 22 July 2009 and the annular eclipse of 15 January 2010 . The main objective behind performing this campaign was detection of TIDs as manifestations of AGWs generated by the movement of the shadow of a solar eclipse. Ionospheric TEC was measured at the three stations for some days around the two eclipses.

During the total solar eclipse on 22 July 2009 between the first contact that occurred at 23:58 UT and the final at 02:01 UT, the early morning growth of ionization following sunrise was significantly halted due to obscuration of the solar disc. As the AGWs are supposed to be generated following the passage of the moon's shadow at a supersonic speed over the surface of the Earth, it was understood that effects of AGWs were more likely to be observed about $1-2 \mathrm{~h}$ after the final contact. Accordingly, measured slant TEC along the tracks of different GPS satellites were analyzed and depletions or bite-outs identified from the 90-min moving average of TEC. However as the period of the 22 July 2009 


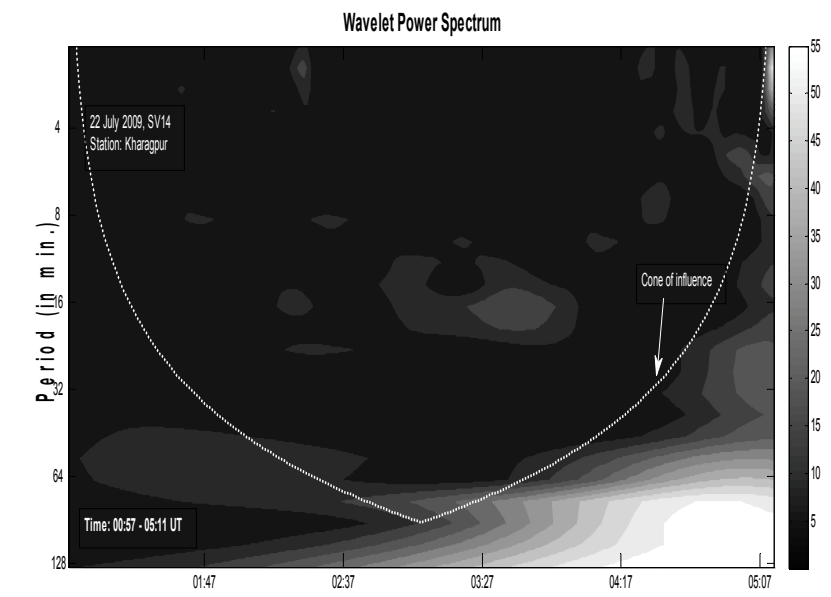

(a)

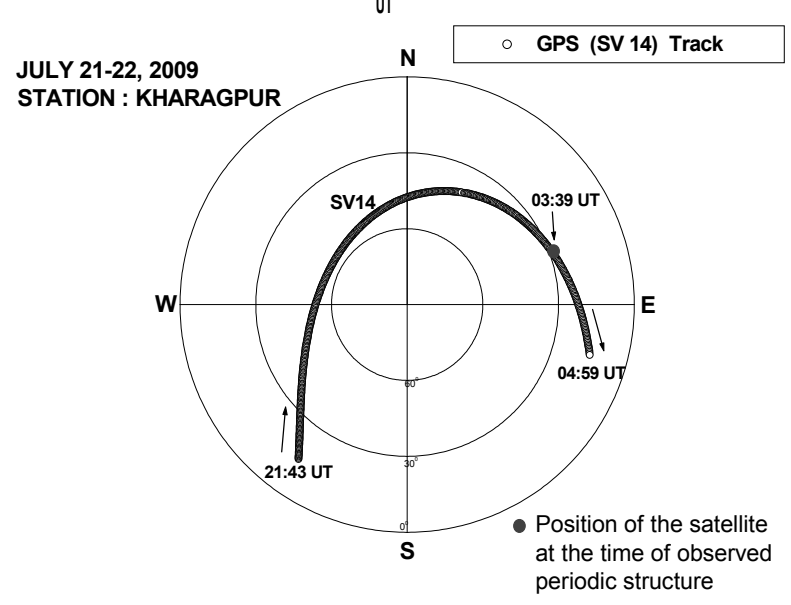

(b) TIME: 21:43 UT OF JULY 21,2009 - 04:59 UT OF JULY 22,2009

Fig. 8. Wavelet transform corresponding to deviations of the slant TEC from the 90-min moving average recorded on the SV14 link during a period 00:57-05:11 UT on 22 July 2009 is shown in (a). Periodic structures of period about $16.6 \mathrm{~min}$ corresponding to the eye of the contour were indicated by the wavelet transform application around 03:39 UT. At that time, the satellite was located northeast of Kharagpur as evident from the polar plot of (b). The white dotted line indicates the cone of influence within which results are reliable.

total solar eclipse corresponds to local early morning hours of very low sunspot number year, the ambient level of ionization was very low. On 22 July 2009 a number of GPS links, notably, SV14, 16 and 31 exhibited a series of depletions in TEC along their tracks with amplitudes in excess of 1 TEC units at elevations greater than $30^{\circ}$. An overwhelming $73 \%$ of the TEC bite-outs were observed within 1-3 h after the final contact at 02:01 UT.

Occurrences of TIDs are supposed to be indirect validation of the generation of AGWs. A more direct mechanism involving performing a wavelet transform of the measured slant TEC provided means of characterization of wavelike structures, if any. Waves have been identified on some GPS links located north-east and south-east of the station at

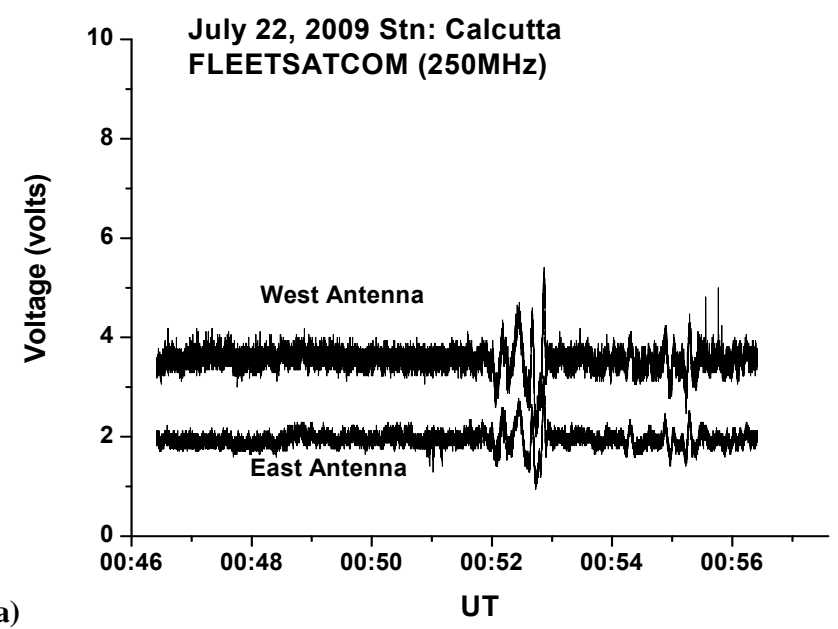

July 22, 2009 FLEETSATCOM 00:52-00:53 UT

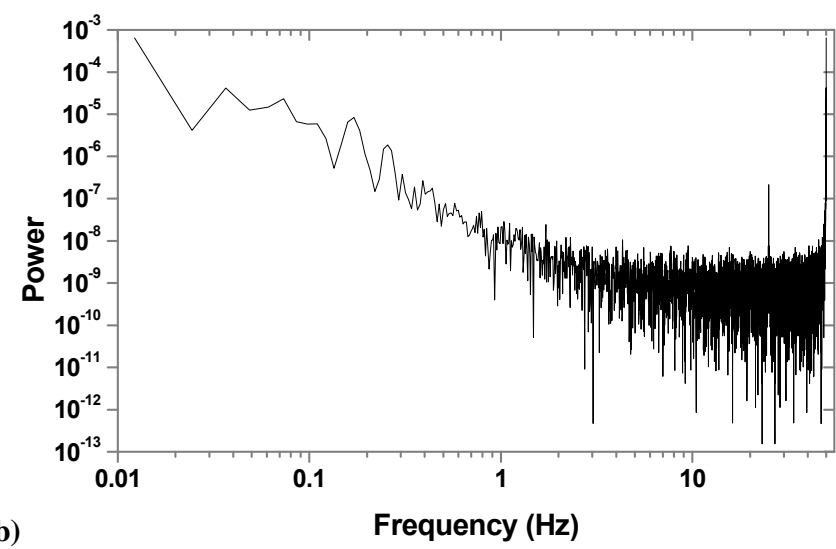

Fig. 9. The patch of amplitude scintillation observed on the VHF link from Calcutta on two antennas is shown in (a) while (b) shows the corresponding power spectrum during 00:52-00:53 UT.

Kharagpur. However the periods found were different from earlier reported values possibly due to shorter distances of the stations presently used from the umbra region. During the annular eclipse on 15 January 2010, the diurnal maximum value of TEC around 08:30 UT was noticeably lower in comparison to the preceding and the following day. Periodic structures have been identified on this occasion too on some GPS links. However a more detailed analysis along these lines will be necessary for improved understanding of the wave features.

The source of the AGWs could be located by combining observations from the three stations using the technique of reverse ray-tracing. As the propagation of the disturbances is aspect sensitive, the distance between the stations with baselines of the order of $200 \mathrm{~km}$ will be desirable to observe similar features of the TIDs and the source of the TIDs may be located with suitable methods of ray tracing and triangulation. 


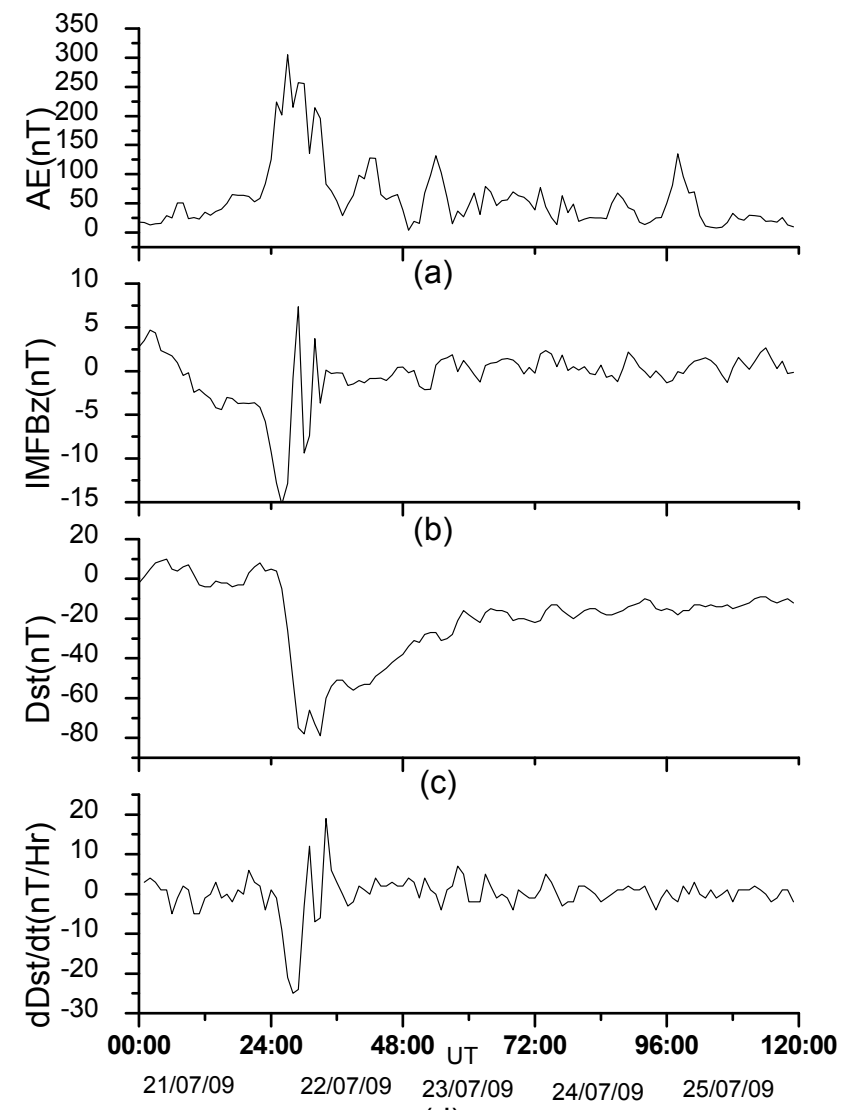

(d)

Fig. 10. The variation of $\mathrm{AE}, \mathrm{IMF} B_{\mathrm{Z}}$, Dst, $d \mathrm{Dst} / d t$ during $21-$ 25 July 2009.

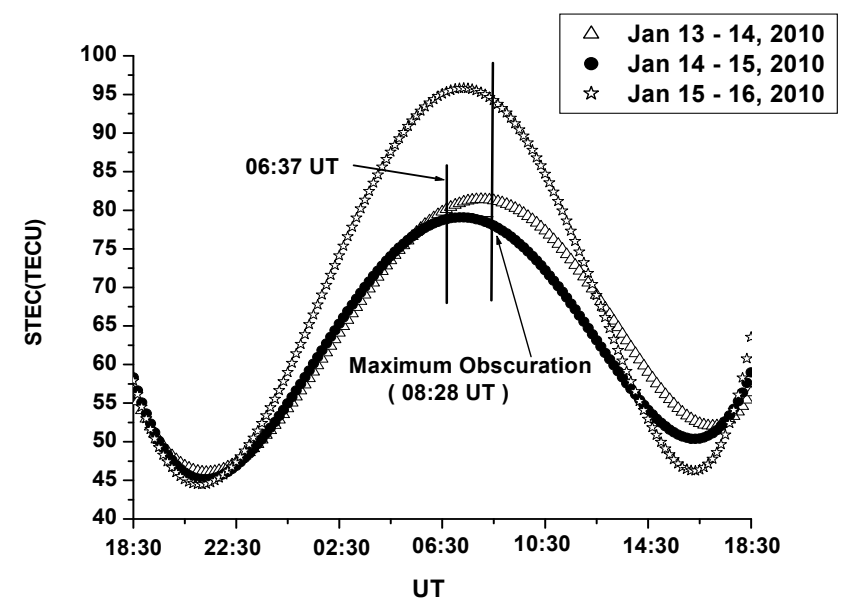

Fig. 11. The best-fit diurnal plots using a polynomial curve of degree 5 corresponding to the period 13-14 January through 1516 January 2010.

The presence or absence of TIDs associated with total solar eclipse has been the subject of investigations over last four decades. Periodic structures in ionization/TEC are om-
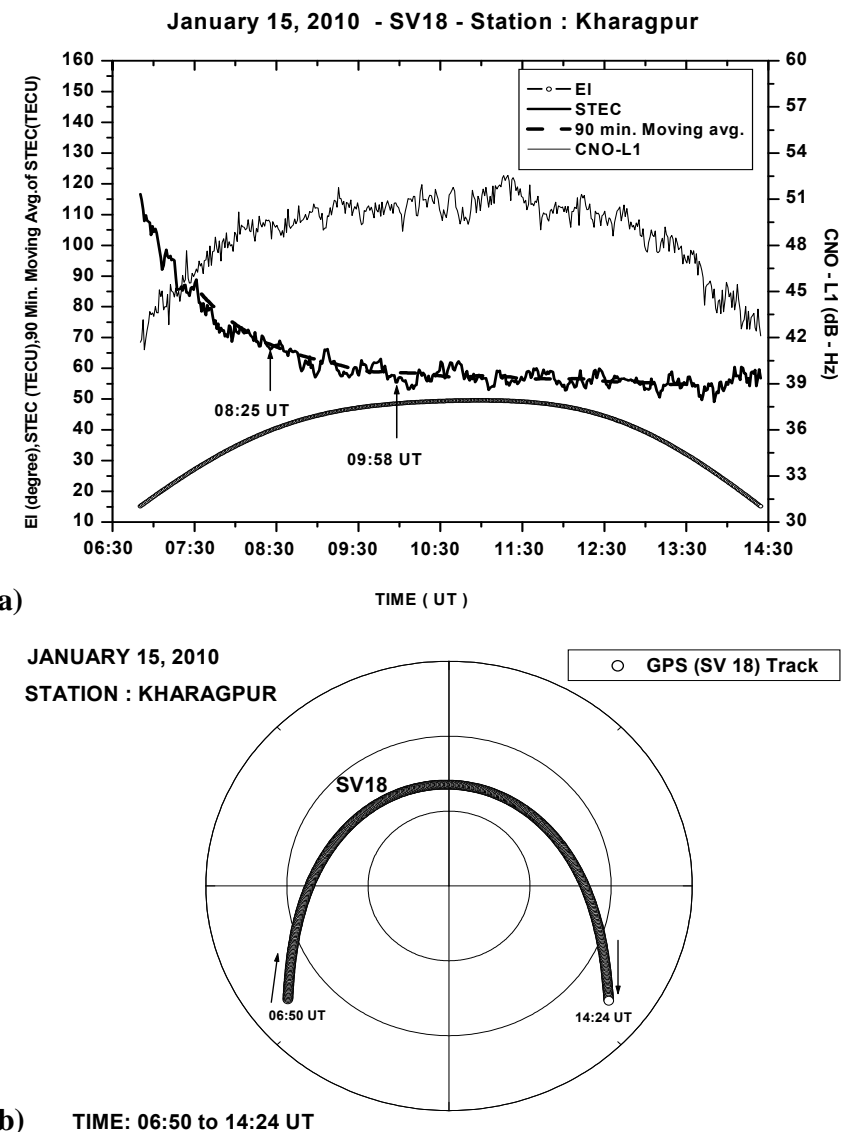

(b)

TIME: $06: 50$ to $14: 24$ UT

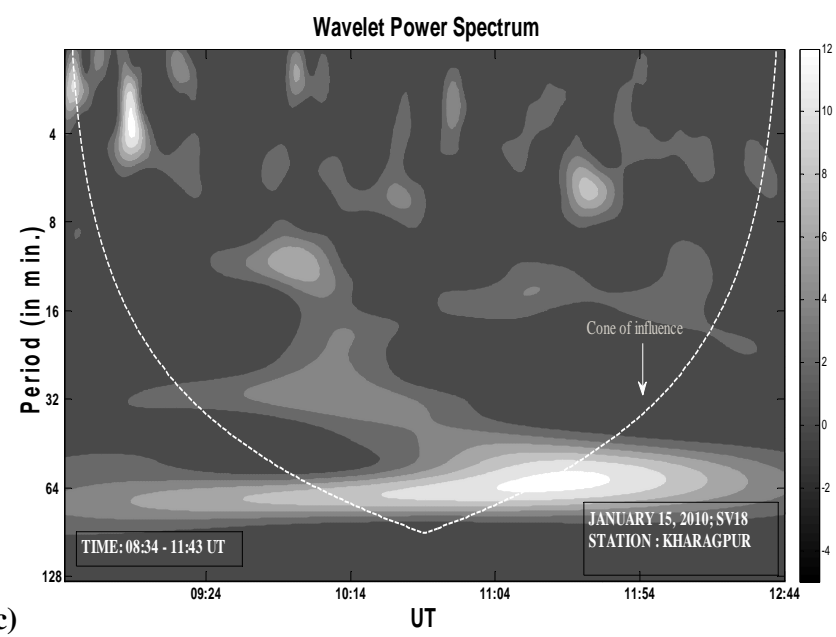

Fig. 12. Variation of slant TEC (STEC), elevation angle, 90-min moving average and carrier-to-noise ratio at GPS L1 frequency (CNO-L1) along the track of SV18 during 06:50-14:24 UT of 15 January 2010 is shown in (a) and the corresponding polar plot from Kharagpur is shown in (b). Waves with periodicities of $8 \mathrm{~min}$ were detected in the wavelet spectrum of deviations in TEC from the 90-min moving average recorded on the SV18 link around 10:35 UT as depicted in (c). At that time, the satellite was located almost due north of the station as shown in (b). The white ellipse indicates the cone of influence within which results are reliable. 
nipresent both subsequent to an eclipse as well as on normal days. However in the present case prominent features of quasi-periodic fluctuations are observed subsequent to the passage of the eclipse shadow in contrast to the mild structures recorded on other days as shown in Fig. 6b. The mechanism of association of the periodic structures and the supersonic movement of the umbra region cannot be uniquely established from any one type of observation. The Atmospheric Gravity Waves may be one of the candidates for the same. Moreover a magnetic storm in progress on 22 July 2009 may also be responsible for the contamination of the structures and large scale features of TEC.

Acknowledgements. This research has been sponsored in part by the Indian Space Research Organization (ISRO) through the CAWSES Program and the Asian Office of Aerospace Research and Development (AOARD) through the SCINDA program. The authors would like to acknowledge the support extended by A. Jeyaram, Director, ISRO Regional Remote Sensing Service Center, Kharagpur, India and S. Roy, Principal, and K. Basu, Faculty, K. N. College, Baharampore, India for conducting the experiments.

Topical Editor P.-L. Blelly thanks two anonymous referees for their help in evaluating this paper.

\section{References}

Altadill, D., Sole, J. G., and Apostolov, E. M.: Vertical structure of a gravity wave like oscillation in the ionosphere generated by the solar eclipse of 11 August 1999, J. Geophys. Res., 106, 2141921428, 2001.

Chen, G., Zhao, Z., Zhou, C., Yang, G., and Zhang, Y.: Solar eclipse effects of 22 July 2009 on Sporadic-E, Ann. Geophys., 28, 353357, doi:10.5194/angeo-28-353-2010, 2010.

Chimonas, G.: Internal gravity-waves motions induced in the Earth's atmosphere by a solar eclipse, J. Geophys. Res., 75, 5545-5551, 1970.

Chimonas, G.: Lamb waves generated by the 1970 solar eclipse, Planet. Space Sci., 10, 1843-1854, 1973.

Chimonas, G. and Hines, C. O.: Atmospheric gravity waves induced by a solar eclipse. J. Geophys. Res., 75, 875, 1970.

Chimonas, G. and Hines, C. O.:. Atmospheric gravity waves induced by a solar eclipse, 2, J. Geophys. Res., 76, 7003-7005, 1971.

DasGupta, A., Maitra, A., Das, S. K., and Sen, S. K.: Ionospheric electron content observations during the total solar eclipse of February 16, 1980, J. Atmos. Terr. Phys., 43, 135-137, 1981.

Davies, K., Fritz, R. B., and Gray, T. B.: Measurements of the Columnar Electron Contents of the Ionosphere and Plasmasphere, J. Geophys. Res., 81, 2825-2834, 1976.

Davis, M. J. and da Rosa, A. V.: Possible Detection of Atmospheric Gravity Waves generated by the Solar Eclipse, Nature, 226, 1123, 1970.
Deshpande, M. R., Chandra, H., Sethia, G., Vats, H. O., Vyas G. D., Iyer, K. N., and Janve, A. V.: Effects of the total solar eclipse of 16 February 1980 on TEC at low latitudes, Proc. Ind. Natn. Sci. Acad., 48A, 427-433, 1982.

Farges, T., Jodogne, J. C., Bamford, R., Le Roux, Y., Gauthier, F., Vila, P. M., Altadill, D., Sole, J. G., and Miro, G.: Disturbances of the western European ionosphere during the total solar eclipse of 11 August 1999 measured by a wide ionosonde and radar network. J. Atmos. Sol.-Terr. Phys., 63, 915-924, 2001.

Fritts, D. C. and Luo, Z.: Gravity wave forcing in the middle atmosphere due to reduced ozone heating during a solar eclipse, J. Geophys. Res., 98, 3011-3021, 1993.

Hanuise, C., Broche, P., and Ogubazghi, G.: HF Doppler observations of gravity waves during the 16 February 1980 solar eclipse, J. Atmos. Sol.-Terr. Phys., 44, 963-966, 1982.

Liu, J. Y., Hsiao, C. C., Tsai, L. C., Liu, C. H., Kuo, F. S., Lue, H. Y., and Huang, C. M.: Vertical phase and group velocities of internal gravity waves from ionograms during the solar eclipse of 24 October 1995, J. Atmos. Sol.-Terr. Phys., 60, 1679-1686, 1998.

Sauli, P., Abry, P., Boska, J., and Duchayne, L.: Wavelet characterization of ionospheric acoustic and gravity waves occurring during the solar eclipse of 11 August 1999, J. Atmos. Sol.-Terr. Phys., 68, 586-598, 2006.

Singh, L., Tyagi, T. R., Somayajulu, Y. V., Vijayakumar, P. N., Dabas, R. S., Loganadham, B., Ramakrishna, S., Rama Rao, P. V. S., Dasgupta, A., Naneeth, G., Klobuchar, J. A., and Hartmann, G. K.: A multi-station satellite radio beacon study of ionospheric variations during solar eclipses, J. Atmos. Sol.-Terr. Phys., 51, 271-278, 1989.

Singleton, D. G.: Power spectra of ionospheric scintillation, J. Atmos. Sol.-Terr. Phys., 36, 113-133, 1974.

Tyagi, T. R., Singh, Lakha, Vijaykumar, P. N., Somayajulu Y. V., Loganadham, B., and Yellaiah, G.: Satellite Radio Beacon Study of the Ionospheric Variations at Hyderabad during the Total Solar Eclipse of February 16, 1980, Bull. Astro. Soc. of India, 8, 6972, 1980.

Vadas, S, L.: Horizontal and vertical propagation and dissipation of gravity waves in the thermosphere from lower atmospheric and thermospheric sources, J. Geophys. Res., 112, A06305, doi:10.1029/2006JA011845, 2007.

Van Zandt, T. E., Norton, R. B., and Stonehocker, G. H.: Photochemical rates in the equatorial $F_{2}$ region from the 1958 eclipse, J. Geophys. Res., 65, 2003-2009, 1960.

Zerefos, C. S., Balis, D. S., Meleti, C., Bais, A. F., Tourpali, K., Kourtidis, K., Vanicek, K., Cappellani, F., Kaminski, U., Colombo, T., Stubi, R., Manea, L., Formenti, P., and Andreae, M. O.: Changes in surface solar UV irradiances and total ozone during the solar eclipse of11 August, 1999, J. Geophys. Res., 105, 26463-26473, 2000. 